\title{
Environmental and Psychosocial Factors into Polices Designed to Promote Drinking Water Consumption among Children and Adolescents
}

\author{
Arely Vergara-Castañeda ${ }^{1, *}$, María de los Angeles Peña-Farfán ${ }^{1}$, Donovan Raúl Ríos-Hernández \\ Laura Martino-Roaro ${ }^{1}$, Edgar Vergara $C^{1,2}$, César Jesús Sandoval-García ${ }^{1}$, \\ Ma. Rosario Ayala Moreno ${ }^{1}$ \\ ${ }^{1}$ Research Group in Basic and Clinical Health Sciences, Facultad de Ciencias Químicas, Universidad La Salle, Mexico \\ ${ }^{2}$ Thoracic Oncology Unit, Instituto Nacional de Cancerología, Mexico
}

Copyright $@ 2018$ by authors, all rights reserved. Authors agree that this article remains permanently open access under the terms of the Creative Commons Attribution License 4.0 International License

\begin{abstract}
Low drinking water intake in Mexico is considered a public health problem due to its linkage with some other negative factors related to lifestyle and eating behavior. Choosing beverages is the result of the interaction between physiological mechanisms, common knowledge and social context; including social interaction, availability, convenience, marketing, peer pressure and cultural practices. Until recently, there was limited interest on these ecological factors related to water consumption in Mexican children and adolescents. Understanding the relationships among this population habits and psychosocial or environmental factors, which shape drinking behavior, will enable the identification of specific populations at the risk of low water intake and allow to understand the problem of low drinking water consumption and the need to consider this factors while planning an strategy or policy to improve water intake among children and adolescents. In Mexico, one sixth of the population has no access to drinking water and almost $40 \%$ lack basic sanitation. These figures are worse in marginalized vulnerable urban communities where it has been suggested that only $18 \%$ of children and adolescents reach water consumption recommendations. As this population spends most of their time in schools and home, these places should been considered key places to promote water consumption as long as the availability, quality of water, sociodemographic conditions, water security, and social norms/cultural behaviors being ensured. Despite drinking water promotion has gained a global spotlight and even though numerous campaigns and policy interventions to promote water intake has been considering for creating population-wide improvements in health behavior, there is a need to innovate campaigns and widespread government public health initiatives through a novel approach which involves multicomponent
\end{abstract}

environmental modification. Thus, in this paper, we provide an overview of the major environmental and psychosocial factors related to water consumption behavior that should be considered to guarantee a better impact of drinking water policies.

Keywords Water Intake, Psychosocial Factors, Policies, Children, Adolescents

\section{Highlights}

- $\quad$ There is limited information about psychosocial and environmental factors related to water consumption in Mexican children and adolescents.

- There is a need to provide an overview of the major challenges and opportunities related to plain water intake.

- Recognizing environmental and psychosocial factors would improve the design and implementation of policies aimed to increase water consumption.

\section{Introduction}

Water is the major constituent of the human body [1] and drinking water including any source considered for human use and consumption, which could include tap water, plain water, well water or bottled water that guarantees permissible limits of quality for physicochemical and organoleptic characteristics. [2] Water should be considered as the most important source to fulfill for almost all the hydration needs of a healthy human $[3,4]$. If not, the recommended daily fluid intake could be complemented by drinking other beverages 
according to individual preferences what would allow variation in diet [3].

While the need to ingest water in general responds mainly to physiological mechanisms like thirst, different factors can contribute to the ingestion of fluids or any other beverage [3]. The choice of drink is the result of personal judgments that make use common knowledge and other forms of the social context of the subjects [4], including social interaction, availability, convenience, marketing, peer pressure and cultural practices [5].

Also, according to the World Health Organization, not only physical environmental, biological or chemical factors affect human health, but also environmental and psychosocial factors. In this sense, the current ecological approach in health behavior research recognizes that health behavior needs to be understood in a broad environmental context, including "all factors external to the individual" [6, 7]. This has led to an exponential increase in the number of studies on this topic.

Despite health promotion has gained a global spotlight and even though numerous innovate campaigns and policy interventions to promote water intake have been considered as promising strategies for creating population-wide improvements in health [8, 9, 10, 11], no clear overview exists of environmental factors that have consistently been shown related to water consumption and there is limited information on the extent to which characteristics are associated with this behavior among children [12] and adolescents [13], making it clear that a novel approach is required. Thus, this paper provides an overview of the major policy challenges and opportunities related to environmental factors that influence water intake to emphasize the need for multicomponent strategies (access, social campaigns, social empowerment and psychosocial factors) to attain the recommended levels of water consumption in Mexican children.

\section{Methodology}

These settings provide a potential means for general pediatricians or health' professionals to improve water intake considering an overview of environmental and social factors that should be included into strategies aimed at increasing water consumption in children and adolescents as stated in the National Food Health Agreement (Acuerdo Nacional de Salud Alimentaria) in Mexico, according to the socio-demographic characteristics of elementary schools given that this agreement focus solely on increasing the availability, accessibility and consumption of simple drinking water as part of the priority objectives [14].

The fluid intake for healthy subjects can vary markedly depending on activity level, environmental exposure, diet, and social activities [15], so that; we realized an open comprehensive review of the literature. The rationale for conducting a review was to determine the relevant data investigating the extent to which the current literature addressed to describe various environmental factors that could play a decisive role in the trend of plain water consumption among children and adolescents, putting them at risk for not accomplishing the recommendations and discuss a direction for developing specific child welfare policy for vulnerable groups.

\section{Results}

\section{Availability and Sociodemographic Conditions}

There are several choices in drinking water provision (e.g., bottled water consumption, home-based water treatment or installation of water storage facilities), which can be adapted to the existing water supply system in urban communities where we cannot ensure access to potable water. In the case of water treatment systems, its use range from 3.9 to $14.8 \%$ of the population in U.S.A. especially in upper-income suburban homeowners [16, 17] with no available data in Mexico.

Despite one approach for promoting water intake is to make free potable drinking water widely accessible in public facilities with favorable results $[18,19,20]$, and provide drinking water in schools for consumption and restrict the availability of other beverages $[3,21]$. Current polices to promote drinking water are focused only on the installation of water fountains in schools (some reports estimated that $55 \%$ of public elementary schools have this service) without considering availability at home. Some characteristics of public schools in Mexico include the inability to provide drinking water to students and the lack of basic sanitation. These figures are worse in marginalized vulnerable urban communities where only $18 \%$ of children and adolescents accomplish water consumption recommendations [22].

School districts are required by the federal government to make drinking water available to students at no charge in the food service areas during all school meals. Schools can decide how to serve the water, notwithstanding the efforts provides by the National policies, children and adolescents may not drink from fountains because they could be few in number, may be unavailable in key schools locations, or may not be accompanied by vessels that allow for more than a sip of water at a time [23]. Also, broken water fountains and long lines to get water have been suggested as other barriers [24].

\section{Water Security}

Water as an essential sustains to life, and a satisfactory supply must be available for all [25]. This term includes not only the promotion of access to adequate and safe water, as protection of the vulnerable population from risk 
of water-related hazards but at an affordable cost for every person [26, 27].

As drinking water is a potential source of human exposure to a variety of contaminants; microbiological, chemical or radiologic [25] and young children are more sensitive than adults to toxic chemicals commonly found in tap water [28] ensuring access to safe drinking water is a major public health concern.

\section{Attitudes/ Social Norms/ Cultural Behaviors}

Despite the availability of any source of water, it has been suggested that people exposed to insensible water loss due to environmental circumstances do not drink enough water [29, 30], where children are known to be at a greater risk than adults for this voluntary and chronic dehydration [31]. Also, previous studies have suggested that there are disparities in the type of water consumed, with children and adolescents from households of lower educational levels and Latinos being more likely to purchase bottled water than to drink tap water [23].

Although tap water is readily available in some settings or schools at a low-cost, studies have suggested that many young people do not drink from fountains because they consider them unclean or the water unpalatable or unsafe [23, 32, 33] and believe it could cause illness, thus the majority opt for bottled water instead [34, 35, 36], whit a positive trend in the last years, estimating that more than $50 \%$ of the population drinks bottled tap water [37].

Societal norms, culture as well as individual knowledge and attitudes influence behaviors associated with weight status, so it is possible that low intake of drinking water may be associated with other less-healthful behaviors as practicing physical activities or eating behavior [13]. Also, taste preferences, being told to drink certain type of water and convenience have been cited as reasons why individuals may not drink tap water [23, 37]. According to this, it has been reported that water is consumed not only as drinking water but also as food and other kind of beverages.

Other factor that has been identified in avoidance of water is the safety concerns due the Mexican cultural beliefs about poor water quality, perceived health risks and illness that may not be comparable with other ethnic or geographic groups [35, 37]. In this sense it remains important to identify the type or water that is consumed and the process in which it was purified (type of filter, boiling process, use of chlorine) in order to increase the ability of clinical personnel to give appropriate anticipatory guidance about water consumption.

\section{Home Food Environment}

The home food environment predicts the drinking pattern of children, where the factor most strongly associated with low drinking water intake was frequent consumption of snacks while watching television or movies and some other indicators of poor diet quality [18]. Efforts to increase water consumption may need to consider low daily water intake as part of a cluster of other less-healthful behaviors and should focus on those with these associated factors [13].

\section{Discussion: Insights for Future Applications}

The growing interest in promoting optimal drinking strategies has focused its attention at schools because they are considered as an ideal forum for influencing the hydration status and the impact of this kind of strategies has been demonstrated [31], where the habitual water intake at school, in which the access to water is limited (no fountains available, no water on the desk), is characterized by a marked tendency of the children to do not drink water during school day, which in turns in and low levels of hydration [31] and in an high proportion of children who consumed less than the recommended daily amount of fluid [22, 38, 39].

On the other hand, behavioral factors associated with low water intake and knowledge of the beneficial effects of drinking water at school is of particular interest for school polices, which are known to heavily influence children's water consumption [31]. In this sense, health concerns and some negative attitudes related to drinking habits may play an important role as they are associated with intention to drink water at school and this to overall water intake among students, thus altering the school environment to make free and appealing water more readily accessible may be insufficient to increase consumption. To counter students concerns regarding safety of water it would be necessary the implementation of a testing system to assess water for contaminants and communicating water quality to school community [23]. In case it is not possible to guarantee the provision of safe tap water, schools should look up for some other short-term strategies.

Bottled water, filtered and tap water are generally safe in the United States [37]. However, throughout the Mexican territory access to simple water is limited [14] and water system does not guarantee the safety of this liquid. Because cost, also has been cited as a barrier, schools may also want to consider lower costs strategies such as retrofitting existing drinking fountains to include bottle filter attachments or installing nonfountain drinking water sources in a few high-traffic locations or provide nonfountain sources of drinking water as water stations with reusable bottle fillers or water cup dispensers to increase water intake at schools [19, 23, 40].

On the other hand, though students may have access to water, some internal policies such as allowing them to have water bottles on their desk or restricting water during 
class may prevent them from drinking enough [38].

Regarding some eating behaviors that may be considered to improve daily fluid intake, snacking is the one that was shown a high impact on the overall water intake, including tap water, bottled water or purified [41] at home as well as at school for a clinically significant impact on water intake [42].

Despite the abundance of evidence-based guidance for clinicians and communities, innovate campaigns and widespread government public health initiatives, it is clear that a novel approach is required [43], in which convincing the public to adopt and maintain sustainable behaviors, such as drinking water is a challenging task with the potential for significant physiological, environmental and social benefits [32, 44]. One strengthen of this article is that it takes an initial step toward the inclusion of social factors so that design could be accurate and to make the impact stronger.

The evidence provided by this analysis related to drinking practices is relevant in order to provide helpful information to shape up public health policies or programs aimed to promote healthy drinking practices of water among children and adolescents at schools.

\section{Conclusions}

Low water intake is considered a public health problem due the linkage between this and some other negative factors related to lifestyle and eating behavior, resulting in a an important area for both, scientific inquiry and policy development. So that, there are several windows of opportunity for interventions and polices aimed to increase plain water consumption in children and adolescents, and these should involve not only multicomponent environmental modifications aimed to ensure access to drinking water at schools, but also consider broader psychosocial factors. In this paper we proposed that the inclusion of these factors and social marketing might facilitate the development of effective strategies for promoting appropriate drinking patterns at school and outside it.

\section{Conflict of Interest}

The authors declare that they have no conflict of interest.

\section{Acknowledgements}

This project was supported by Universidad La Salle, Mexico (Registered project: SAL-11/16).

\section{REFERENCES}

[1] Jéquier E, Constant F. Water as an essential nutrient: the physiological basis of hydration. Eur J Clin Nutr. 2010; 64(2): 115-123.

[2] Secretaría de Salud. Norma Oficial Mexicana NOM-127-SSA1-1994, Salud Ambiental, Agua para uso y consumo humano: Límites permisibles de calidad y tratamientos a que debe someterse el agua para su potabilización. Diario Oficial de la Federación DVIII. 1994, 13.

[3] Rivera JA, Muñoz-Hernández O, Rosas-Peralta M, Aguilar-Salinas CA, Popkin BM, Willett WC, et. al. Beverage consumption for a healthy life: recommendations for the Mexican population. Salud Pública Mex. 2008; 50 (2): 173-195.

[4] Espinosa-Montero J, Aguilar-Tamayo MF, Monterrubio-Flores EA, Barquera-Cervera S. Knowledge about consumption of plain water in adults of low socioeconomic status of the city of Cuernavaca, México. Salud Pública Mex. 2013: 55 (Suppl 3): 423-430.

[5] Martínez H. Fluid intake in Mexican adults; a cross-sectional study. Nutr Hosp. 2014; 29(5): 1179-1187.

[6] Sallis JF, Owen N. Fisher EB. Ecological models of health behavior. En: Glanz, K., Lewis, F.M., Rimer, B.K., (eds). Health Behaviour and Health Education. Theory, Research and Practice. $5^{\text {th }}$ Edition. San Francisco: Jossey-Bass, 2015; 5 p. $43-64$.

[7] Campbell KJ, Crawford DA, Salmon J, Carver A, Garnett SP, Baur LA. Associations between the home food environment and obesity - promoting eating behaviors in adolescence. Obesity, 2007; 15(3): 719-730.

[8] Hill Jo, Wyatt HR, Reed GW, Peters JC. Obesity and the environment: where do we go from here? Science. 2003; 299(5608):853-855.

[9] Feng J, Glass TA, Curriero FC, Stewart WF, Schwartz BS. The built environment and obesity: a systematic review of the epidemiologic evidence. Health \& place. 2010; 16(2): 175-190.

[10] Stokols D, Grzywacz JG, McMahan S, Phillips K. Increasing the health promotive capacity of human environments. Am J Health Promotion 2003; 18(1): 4-13.

[11] Richard L, Gauvin L, Raine K. Ecological models revisited: their uses and evolution in health promotion over two decades. Annu. Rev. Public Health. 2011; 32: 307-326.

[12] Kant AK, Graubard BI. Contributors of water intake in US children and adolescents: Associations with dietary and meal characteristics-National Health and Nutrition Examination Survey 2005-2006. Am J Clin Nutr. 2010; 92 (4): 887-896.

[13] Park S, Sherry B, O’Toole T, Huang Y. Factors associated with low drinking water intake among adolescents: the Florida Youth Physical Activity and Nutrition Survey, 2007. J Am Diet Assoc. 2011; 111(8): 1211-1217.

[14] Acuerdo Nacional de Salud Alimentaria. Estrategia contra el sobrepeso y la obesidad 2010. México: Secretaría de Salud. 2010. 
[15] Institute of Medicine. Dietary reference intakes for water, potassium, sodium, chloride and Sulfate. Washington, DC: The National Academies Press. 2005.

[16] Hedden CR, Crispell D. Water Works: Spending on bottled water, home treatments, and professional water managers now exceeds \$17 billion a year. Mounting problems will push that total much higher. Am Demogr. 1996; 18: 46-54

[17] Tracey S, Anne B. OECD insights sustainable development linking economy, society, environment: Linking economy, society, environment. OECD Publishing. 2008.

[18] Park S, Blanck HM, Sherry B, Brener N, O’Toole T. Factors associated with low water intake among US high school students - National Youth Physical Activity and Nutrition Study, 2010. J Acad Nutr Diet. 2012; 112(9): 1421-1427.

[19] Muckelbauer R, Libuda L, Clausen K, Toschke AM, Reinerhr $T$, Kersting M. Promotion and provision of drinking water in schools for overweight prevention: randomized, controlled cluster trial. Pediatrics. 2009; 123 (4): e661-667.

[20] Patel AI, Bogart LM, Elliot MN, Lamb S, Uyeda KE, Hawes-Dawson J, et. al. Increasing the availability and consumption of drinking water in middle schools: a pilot study. Prev Chronic Dis. 2011; 8(3); A60.

[21] World Health Organization. Guidelines for drinking-water quality. Incorporating the first and second addenda, vol. 1. Recommendations 3rd ed. Geneva. 2008.

[22] Vergara-Castañeda A, Martínez-Valdivia M, Gómez-Martínez MA, Castillo-Martínez L, Martino-Roaro L, Ayala-Moreno MA. Water intake in Mexican adolescents. Differences regarding the presence of cardiovascular risk factors. Nutr Hosp. 2015; 32(2): 50

[23] Patel AI, Bogart LM, Klein DJ, Burt Cowgill, Uyeda KE, Hawes-Dawson J, et. al. Middle school student attitudes about school drinking fountains and water intake. Acad Pediatr. 2014; 14(5); 471-477.

[24] Onufrak SJ, Park S, Sharkey JR, Merlo C, Dean WR, Sherry B. Perceptions of tap water and school water fountains and association with intake of plain water and sugar-sweetened beverages. J Sch Health. 2014; 84 (3): 195-204.

[25] World Health Organization. Guidelines for drinking-water quality. First addendum to third edition, vol. 1. Recommendations - 3rd ed. Geneva. 2006.

[26] World Water Council. Declaration of The Hague: Ministerial declaration of The Hague on water security in the 21st century. The Hague: Second World Water Forum. 2000.

[27] Rahaman MM, Varis O. The Mexico World Water Forum's Ministerial Declaration 2006: A Dramatic Policy Shift? International Journal of Water Resources Development. 2008; 24(1): 177-196.

[28] Levallois P, Gingras S, Caron M, Phaneuf D. Drinking water intake by infants living in rural Quebec (Canada). Sci Total Environ. 2008; 397 (1-3): 82-85.

[29] Greenleaf JE, Sargent F. Voluntary dehydration in man. J Appl Physiol. 1965; 20 (4): 719-724.
[30] Cheuvront SN, Kenefick RW. Dehydration: physiology, assessment, and performance effects. Compr. Physiol. 2014; 4:257-285.

[31] Fadda R, Rapinett G, Grathwohl D, Parisi M, Fanari R, Calò $\mathrm{CM}$, et. al. Effects of drinking supplementary water at school on cognitive performance in children. Appetite. 2012; 59 (3): 730-737.

[32] Saylor A, Prokopy LS, Amberg S. What's wrong with the tap? Examining perceptions of tap water and bottled water at Purdue University. Environ Manage. 2011; 48 (3): 588-601.

[33] Gorelick MH, Gould L, Nimmer M, Wagner D, Heath M, Bashir $\mathrm{H}$, et. al. Perceptions about water and increased use of bottled water in minority children- Arch Pediatr Adolesc Med. 2011; 165 (10): 928-932.

[34] Olson ED. Bottled water: pure drink or pure hype?. EUA. Editorial National Resources Defense Council. Food and Drug Administration. 1999.

[35] Doria MF. Bottled water versus tap water: understanding consumers' preferences. Journal of Water and Health. 2006; 4(2): 271-276.

[36] Gleick PH, Cooley HS. Energy implications of bottled water. Environ. Res. Lett. 2009; 4(1): 014009.

[37] Hobson WL, Knochel ML, Byington CL, Young PC, Hoff CJ, Buchi KF. Bottled, filtered, and tap water use in Latino and non-Latino children. Arch Pediatr Adolesc Med. 2007: 161(5): 457-461.

[38] Kaushik A, Mulle MA, Bryant TN, Hill CM. A study of the association between children's access to drinking water in primary schools and their fluid intake: can water be 'cool' in school? Child Care Health Dev. 2007; 33(4): 409-415.

[39] Piernas C, Barquera S, Popkin BM. Current patterns of water and beverage consumption among Mexican children and adolescents aged 1-18 years: analysis of the Mexican National Health and Nutrition Survey 2012. Public Health Nutrition 2014; 17: 2166-2175.

[40] Bogart LM, Cowgill BO, Elliot MN, Klein DJ, Hawes-Dawson J, Uyeda K, et. al. A randomized controlled trial of students for nutrition and exercise: a community-based participatory research study. J Adolesc Health. 2014; 55(3): 415-422.

[41] Wang D, van der Horst K, Jacquier E, Elridge AL. Snacking Among US Children: Patterns Differ by Time of Day. J Nutr Educ Behav. 2016; 48(6): 369-375.

[42] Sebastian RS, Wilkinson Enns C, Goldman JD. Drinking water intake in the U.S.: What we eat in America, NHANES 2005-2008. Food Surveys Research Group Dietary Data Brief No.7. United States Department of Agriculture, Agricultural Research Service. 2011.

[43] Armstrong LE, Barquera S, Duhamel JF, Hardinsyah R, Haslam D, Lafontan M. Recommendations for healthier hydration: addressing the public health issues of obesity and type 2 diabetes. Clin Obes. 2012; 2(5-6); 115-124.

[44] Storey JD, Saffitz GB, Rimón JG. Social Marketing. In: Glanz K, Rimer B, Viswanath. Health Education and Health Behavior. Theory, research and practice. Jossey-Bass. $4^{\text {th }}$ Edition. 2008. 